\title{
Prenatal cerebrospinal fluid modulate differentiation and proliferation of rat pheochoromocytoma PC12 cells
}

\author{
Mohammad Nabiuni*, Javad Rasouli, Kazem Parivar, Homa Mohseni Kochesfhani \\ From 54th Annual Meeting of the Society for Research into Hydrocephalus and Spina Bifida \\ Vancouver, Canada. 7-10 July 2010
}

\section{Background}

During the early stages of brain development, ependymal cells that line the neural tube are thought to secrete CSF. It is well documented that fetal CSF contains many neurotrophic and growth factors which are known as modulators of neurogenesis, differentiation and brain extracellular microenvironment. Rat pheochromocytoma PC12 cells have been widely used as an in vitro model of neuronal differentiation since the cells undergo differentiation to sympathetic neuron-like cells in response to NGF, bFGF, EGF, TGF- $\alpha$ and GDNF. We hypothesized that prenatal CSF could have differentiational effect on PC12 cells.

\section{Materials and methods}

CSF was removed by tapping the cisterna magna of Wistar rat fetuses (E17- E20) then centrifuged at 4000 r.p.m for $10 \mathrm{~min}$, the supernatant frozen immediately and stored at $-70^{\circ} \mathrm{C}$ until used. PC12 cells were cultured in RPMI-1640 with $10 \% \mathrm{FBS}, 100 \mathrm{unit} / \mathrm{ml}$ of penicillin, $100 \mathrm{mg} / \mathrm{ml}$ of streptomycin and $5 \% \mathrm{CO} 2$ at $37^{\circ} \mathrm{C}$. For culture experiments, 2*10E4 PC12 cells were added to each well of a 96-well plate that had been coated with Poly-D-Lysine. After attachment, the cells were exposed to CSF at different ages with dissimilar concentration of 7, 10, 25\% (v/v). The cell viability and cell proliferation were measured by MTT assay. The neuronal differentiation of PC12 cells were considered by changes of neurite outgrowth.

\section{Results}

Viability and cell proliferation were significantly elevated in PC12 cells cultured in CSF supplemented medium in
E18 compared with control ones. A significant neuronallike outgrowth appeared as early as Day 3 after the application of the CSF supplemented medium E17.

\section{Conclusions}

It was shown that CSF neurotrophic factors can support normal neurogenesis and promotes proper brain development, neuronal differentiation. It has been reported that CSF can be a survival material on its own with any medium for cerebral cortex primary cultures. Our data are in the same line with pervious studies that clarify crucial role of CSF neurotrophic factors in neuronal differentiation and cell proliferation. Taken together we address PC12 neuronal differentiation and cell proliferation to CSF induction by its components especially growth factors.

Published: 15 December 2010

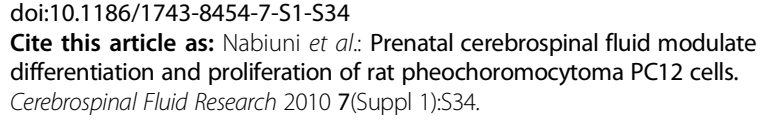

* Correspondence: nabiuni@tmu.ac.ir

Department of Biology Cell and Developmental Research Lab, Tarbiat

Moallem University, Tehran, Iran

(c) 2010 Nabiuni et al; licensee BioMed Central Ltd. This is an open access article distributed under the terms of the Creative Commons 